\title{
Research on Spread of Government Micro Blog
}

\author{
Zhe $\mathrm{Li}^{1, \mathrm{a}}$, Yuqiang Yang ${ }^{2, \mathrm{~b}}$, Houhua Shen ${ }^{3, \mathrm{c}}$ \\ ${ }^{1}$ College of International Exchange, Bohai University, Jinzhou, 121013, China \\ ${ }^{2}$ College of Information Science and Technology, Bohai University, Jinzhou, 121013, China \\ ${ }^{3}$ College of Engineering, Bohai University, Jinzhou, 121013, China \\ a503412508@qq.com, byyq8369@163.com, ’shenhouhuashh@126.com
}

Keywords: government affairs; micro blog; spread; characteristics; mechanism; strategy; function; influencing factors

\begin{abstract}
The current China is creating a service-oriented government, puts forward higher requirements on public management behavior, to good use in the field of public administration of modern media tools. Government affairs micro blog is a new kind of method, electronic micro blog innate advantages during the execution of public management, is the government's public management innovation mode and effective means of information management system. In this paper, the e-government micro blog management related concepts and basic theory study. Relevant concepts mainly studied the micro blog, government affairs micro blog and e-government management; Basic theory research the two-stage transmission theory, two-way symmetry theory, information theory and new public service theory. The research of this paper is management of government affairs micro blog gin-depth study of the early work, which laid a foundation for further research.
\end{abstract}

\section{Introduction}

Government affairs micro blog as a government department and users to interact with the general staff, listen to the opinion of a communication tool, on the one hand, improving the efficiency of the government, on the other hand to help users fully enjoy their rights, fully involved in helping the government improve image and credibility in the public mind. Government affairs micro blog as a kind of network communication, although cannot do comprehensive information, fully replicated government related work, but to a certain extent on the work of the government to supervise and urge. The development of Chinese government affairs micro blog has the following functions [1]: helps to strengthen the government the administrative ability, become the government in the aspect of administrative ability strengthen the quickest, most convenient and most effective way; Helps to improve the government's credibility, for the government departments to provide a more convenient channels of publicity, give full play to the government affairs micro blog the some utility; Help to improve the government's public service, help the government to maintain social stability, promote the government service efficiency.

"Government affairs micro blog" in the "e-government", refers to the government agencies of public affairs .As the subjects of "micro blog asked" e-government micro blog brings together a wide range of public opinion on the one hand, passed the government's governing idea; On the other hand, also exposed many problems, become one of the root of the crisis and upgrade. As a series of bureaucracy and corruption problems exposed in micro blog and diffusion, in politics, the official talk about "micro". For the government, the government affairs micro blog with the other media incomparable advantage [2]. How in this social media platform, and actively to strengthen the construction of the micro blog at the same time, more reasonable and scientific deal with all kinds of crisis seems particularly urgent. This paper researches on the problems related to government affairs micro blog spread, for government affairs micro blog service development. 


\section{Spread Characteristics}

Government affairs micro blog spread has the following features of [3]:

(1) Based on institutional responsibility to strengthen the construction of content and reveal features, shape the image. Use relaxed and concise language and graphic form, let people improve understanding and goodwill in the door of government, to create good government image.

(2) Focus on major events and auxiliary information, highlight the function of public service. Major events information can attract public attention over a period of time, if you want to persistently let user spay attention to micro blog, must release the practical information related to daily life.

(3) To carry out online activities, attract people's attention and participation. Actively develop the network activity, interaction with the general public, the real-time live in micro blog, questions and comments for Internet users, pay attention to the daily life of ordinary citizens.

(4) To ensure credibility, cluster effect into full play. Forwarding microblogging, choose credibility stronger certified organizations and individuals that can support the real information and authority, avoid blindly follow suit, partial to listen to opinions.

(5) Consecutive and regularly release information. When a user to a micro blog began to pay attention to, can produce at any time look forward to the psychological and want to obtain the required information. On the release time is regular, let users form a fixed habits of attention.

(6) Is good at using the network language style to release information. In network era, attention to become the most important resource, use new and varied forms to attract audience's attention, is good at using the common and the popular language, and innovate continuously.

\section{Spread Mechanism}

Information dissemination mechanism, is the form of information transmission, methods, and process each link, including the disseminator, route of transmission, media and the unity of all points such as the receiver. Information dissemination mechanism is a kind of information from the publisher to the recipient's overall generalization of channels. Micro blog information transmission mechanism is essentially it makes the person's social relation is introduced into the information communication, make social relations become an important factor affecting the effects of information dissemination."Five w" model to extract the five key elements in the process of information transmission, all mass communication is the communication effect, for the purpose of the communicator to the audience through the media of information transmission. Information dissemination mechanism model is shown in Fig. 1 [4, 5]. Government affairs micro blog to a certain extent, changed the traditional concept of government transmission mechanism and propagation, but overall, still has the characteristics of mass communication.

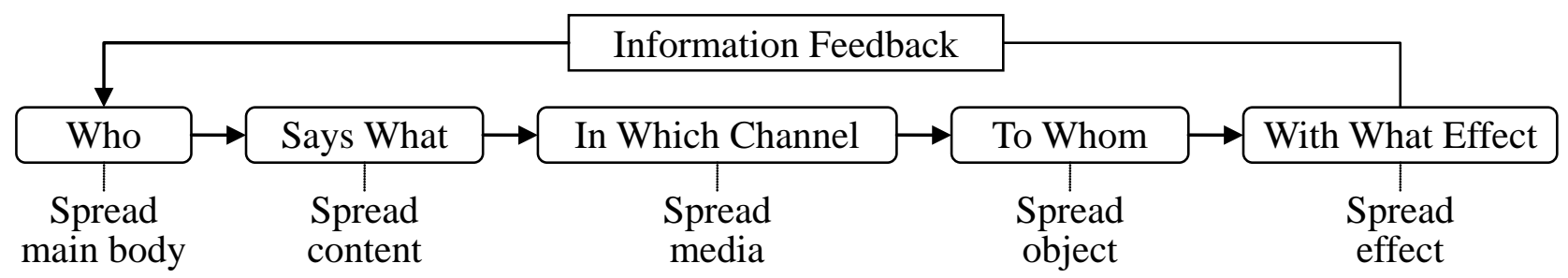

Fig. 1. "5W" model on information spread mechanism

(1) Transmission. In the traditional sense, the spread of the government main body is the government. Government through legal procedure rights policy and decree. In the context of micro blog, the information available to the public is a kind of sharing common resources, in the traditional sense of the government communication effect of the transmission of subject facing the audience. In the era of new media, information transmission from one yuan to multivariate, realized the "all" to all the social communication, everyone is a mouthpiece and radio source. 
(2) The contents. Micro blog context, the government in the process of transmission mechanism transmission content has no much difference with the traditional transmission mechanism, there are mainly the mandatory content, explanatory and publicity content, etc. More government officials and have realized that the basic features of government affairs micro blog is released information on public affairs, rather than a simple administrative told; Is active, artistic expression, rather than a long sermon, follow one's inclinations of individual behavior.

(3) Medium. Media is an essential part of the communication process, the material means of propagation behavior are realized. Micro blog integrated $3 \mathrm{~g}$ and smartphone technology, images, audio and video can be through the computer or mobile phone upload, will print words, visual media images, audio media language symbols such as integrated in the same plane, the realization of audio-visual catalyst of fusion. Must play to the advantages of various media and the accommodation between traditional media and new media, in order to transfer information in the form of convenience.

(4) The spread of the object. Is also known as the receiver or audience, active receivers of information, information promulgator of reprocessing and dissemination activities feedback source, is the motivation and the center link of communication activities. The traditional government spread of audience and micro blog age difference is not big, is mainly related to the people, including all walks, of all ethnic groups, parties, various kinds of social organizations, mass organizations, etc. But each time the government because of the different key points in social affairs, government communications audience object is also different.

(5) Communication effect. Communication effect refers to the disseminator of the media information and transmit it to the audience and the audience thought idea and behavior changes. Micro blog in the context of communication effect is more focused on the interaction of the aspects of audience and subject. Audience can by paying attention to, review, forwarding, micro blog such as direct messages and collection set of feedback mechanism, the implementation and the interaction between the government, is the key to the government communication effect, and not like the traditional government communication effect, the pursuit of the unidirectional, yes or no absoluteness and authority.

\section{Spread Strategy}

According to the characteristics of the spread of government affairs micro blog can adopt the following communication strategy [6-8]:

For the convenience of service theme in independent space, try our best to make everyone more convenient to enjoy the information service, and don't let everyone see government affairs micro blog is only the carrier of the information. Let go of the official languages of the service class information chains, bold attempt unique character, humor and strong original mode of information organization.

To deepen understanding the value of the traditional media, make full use of various communication channels to form resultant force, close cooperation, form a sound and efficient government affairs micro blog overall marketing strategy, in order to form a brand effect in the long term, call for more people to focus on government affairs micro blog, personally involved in the social management.

To research the fan groups can help government affairs micro blog promotion. Composition of micro blog fans, e-government micro blog with its Internet based, helps strengthen the micro blog to ask people of politics and administration supervision, form the officer of the people interaction, promote the micro blog effective transmission. At the same time, to attract more local core target audience, strengthen government affairs micro blog's public opinion influence and communication effect.

E-government WeChat is a mobile service platform of the people's livelihood, are accurate news publishing platform, is zero distance officials and interactive platform, and innovative public service space. Micro We Chat platform will be complementary advantages, to "double micro 
linkage", to assume authority release, political interaction, provide users with all-round government affairs micro service.

\section{Spread Function}

In science and technology, media and social environment, under the function of government affairs micro command to a wide range of application and the universal social consensus, function is gradually extending and extension, including the following aspects:

(1) The government reveal social justice. Open government e-government is the most basic function of micro blog, through government affairs micro blog regularly or irregularly relevant information, the work of the government to introduce all kinds of rules and regulations and policies, procedures, public departments provide supervision means, help the public understanding of government, is the guarantee of building sunshine government and reflect.

(2) To close to the public opinion. In the process of the development of e-government micro blog, the traditional "strong government" is not accepted by netizens, affectionately express way, not only convey the same information, as well as easy to receive the people, can establish friendly image in people's hearts. Should not only consider the people feeling, also want to two or more things government image, give full play to the micro blogging transmission speed, wide coverage and other advantages.

(3) Image propaganda show style. Government affairs micro blog have propaganda function, can not only convey information, to provide convenient service, and can be used as a government or a good name card of the city. Each short information can reflect the blogger represented by the department or the image of the city, can pass the customs of the city.

(4) Public domain communication conducive to maintain stability. The traditional pattern of social and public management in power depends on the government's main means, legal means and economic measures. Social public opinion information media strength is also growing, the impact on the public is becoming more and more big .Government affairs micro blog become the new tool for the government to do public opinion guide, gradually become an indispensable part of social and public management.

\section{Spread Effect Influencing Factors}

E-government micro blog communication effect is solid and comprehensive, transmission through micro blog ACTS on the object, communication object feedback and reaction in the main body, in the process of communication, to this effect, constantly deepen and expand. Government affairs micro blog are many factors that affect the communication effect, sums up as shown in Fig. 2 [9-13].

\begin{tabular}{|c|c|}
\hline \multicolumn{2}{|c|}{ Influencing factors on spread effect for government affairs micro blog } \\
\hline Reliability of information sources & Column of information delivery \\
\hline Emotionality of information content & Controversial of hot topic \\
\hline Empathy of appeal expression & Convenience of information use \\
\hline Practicability of information content & Interactivity active information \\
\hline
\end{tabular}

Fig. 2. Influencing factors on spread effect for government affairs micro blog

(1) Reliability of information sources. Micro blog adulterated information to the disorder of the media market has brought more uncertainty. Some false and flood of junk messages in restricting the fettered people's thoughts, tend to cause adverse effect to the society. Micro blog transmission is information only, not the truth or news. E-government micro blog for the first time the crisis transmit information, usually earlier than some traditional media, micro blog became the most quick 
way to access to information the reliability of the information source has become the focus of attention.

(2) Emotionality of information content. Government affairs micro blog become the government and netizens emotional communication, facilitating the public mood, guide public opinion and the advantage of constructing social consensus platform, mainly reflected in the emotional connection channel, emotional resonance, emotion and emotion from four aspects. Optimize daily information communication, laying the foundation of the emotional connection; To seek a common identity experience, construct the emotional space; Meet the information needs of Internet users, bear the bad social mood; Strive to construct social consensus, the realization of the government and netizens emotional cohesion.

(3) Empathy of appeal expression. Empathy is an alternative emotional response capabilities, can share other people's feelings, situation of empathy for others, is a true feelings in the body is consistent with the other people's mood of emotional experience. Government affairs micro blog asked the government must appeal to the public interests and questions to give attention and respect, can stand on the position of the public thought that the question, with the orientation of the public interest. Better take public demands and opinions, the practical to perform the duties of a service-oriented government for the public to troubleshoot.

(4) Practicability of information content. Practical information refers to the information content of a government affairs micro blog has practical use value, you can directly guide, coordinate and help the audience's life and work, to provide convenient directly. This practical attention to audience's individual life and family life, this is closely related to the interests of the audience. Government affairs micro blog content are mainly concentrated in the spread of life services, government affairs, news and other information, can satisfy the audience's interests, naturally attention.

(5) Column of information delivery. From traditional media's domestic, international, political, and social extension, such as column will be released information classification, on the one hand to facilitate staff screening information, enriching the content of micro blog; Every message has, on the other hand, inductive, facilitate many followers and according to their needs, preferences, and reading habits read selectively or browse, columns formed standard system, release time is relatively fixed, very easy to read, easy to use unified keyword search related information.

(6) Controversial of hot topic. Refers to the subject of government affairs information published micro blog content involves has certain dispute. Controversy has conflict, conflict is one of the important factors lead to participate in the discussion. Conflict reflects information has many, many to make different types of audience can be found in the information and the correspondency of themselves. In the face of government affairs micro blog information, different audience in view of this information when looking for judging principle, according to the different so as to make the audience to inspire each other, keep the continuous discussion of information.

(7) Convenience of information use. Think the government should be public, integration of network resources, as far as possible from the aspects such as time, region and way of attention provide convenience for each other and compress the target audience to pay attention to the time, energy, and the behavior cost, simplify search the search process, provide the public with quick, clarity of information search link address, branch through service platform to provide one-stop service, thereby improving the audience experience satisfaction.

(8) Interactivity active information. E-government micro blog should strengthen the benign interaction with people, truly "ask the people" and "woven bo for the people". Behind virtual government affairs micro blog, corresponding to the real government, on behalf of the government's image and credibility. Government affairs micro blog to equal status into Internet, listen to the people, to the people, asked to. On the basis of the positive interaction and netizens, learn to rational expression, changing subject expression, through tolerance attitude form open dialogue with the public environment.

\section{Conclusion}


The Internet has created unprecedented huge space for public discussion, a surprising number of netizens begin to enter in the field of public affairs, comprehensive and timely information via the Internet, tracking progress of major public events, actively speak and express interests, participation in government decision-making, ultimately affect the country's political and government decision-making. Current micro blog as a new network communication tools have been widely used, opened the micro blog more and more government departments, the micro blog as a new way of transmission of the public policy, government role in the process of the propagation of micro blog in public policy became apparent. The research achievements of this paper to solve the key problems of the government affairs micro blog spread, the healthy and rapid development of e-government micro blog is of great significance.

\section{Acknowledgement}

This work is supported by social science fund project of Liaoning province (L13BGL013): Research on management practice and development strategy of government microblogging in Liaoning province.

\section{References}

[1] D. Tu, "The development and trend of China's government Microblog," Master's degree of Shenyang Normal University, 2014.

[2] Y. Xu, "The Communication Management of Administrative Microblogging in China," Master's degree of Huazhong University of Science and Technology, 2012.

[3] people.cn, "Discussion on the communication characteristics and development of government micro blog," http://media.people.com.cn/n/2012/1106/c224604-19514867.html, 2016-1-5

[4] Z. M. Liang, "On the communication mechanism of government micro blog," Journalism Lover, vol. 27, no. 24, pp. 35-36, 2012.

[5] J. Y. Gan, "The study about the impact factors of different types of government microblogs' propagation," Master's degree of Beijing University of Posts and Telecommunications, 2015.

[6] F. Ren, "Government micro-blog functional orientation and communication skills," Master's degree of Jinan University, 2015.

[7] J. Yu, X. S. Fu, "Research on the function orientation and communication strategy of government micro blog," Library and Information Service, vol. 57, no. S1, pp. 251-255, 2013.

[8] F. Ji, "On the communication strategy of government micro blog under the multi word game," Journalism Knowledge, vol. 30, no. 8, pp. 31-32, 2013.

[9] Y. L. Cai, "Research on the emotional interaction between government micro blog and Internet public opinion," Media Observer, vol. 31, no. 11, pp. 22-23, 2014.

[10] H. L. Chang, "Government Affairs Microblog Communication Effect Evaluation Research in Government Marketing Theory Perspective," Master's degree of East China University of Science and Technology, 2013.

[11] X. P. Hang, Y. B. Li, "The role of government micro blog in the construction of government public relations," Contemporary Communication, vol. 30, no. 6, pp. 73-76, 2014.

[12] F. Fang, "Research on the influence of news release on government microblog," Journal of the South, vol. 26, no. 10, pp. 13-15, 2014.

[13] J. X. Huang, "Problems and suggestions on the current government micro blog in China," Doc in Douding: http://www.docin.com/p-836759465.html, 2016-1-5 